\title{
A importância do direito como tema das redações
}

\author{
Francisco Antonio Morilhe Leonardo*
}

\begin{abstract}
Resumo
O texto reflete a relevância jurídica como tema das redações constantemente enfatizada nas coletâneas das principais bancas avaliadoras dos vestibulares e do Exame Nacional do Ensino Médio. Argumenta-se que a busca de mais igualdade na efetivação a esse direito pressupõe uma ação mais efetiva sendo absolutamente necessário o empenho do Estado para ampliar substantivamente os investimentos em educação, proporcionando aos jovens conhecimentos que dizem respeito aos direitos de todo cidadão, pois é papel da educação e do Estado contribuir para o processo de solidificação dos Direitos Humanos e da construção da cidadania, cujo fundamento se encontra no texto constitucional brasileiro.

Palavras-chave: Redação; Direito; Educação; Formação intelectual e crítica; Princípio da Dignidade da Pessoa Humana.
\end{abstract}

\section{The importance of law as the subject of essays}

\begin{abstract}
The text reflects the juridical relevance as a theme of the essays constantly emphasized in the collections of the main vestibular evaluators and the National High School Examination. It is argued that the search for more equality in the realization of this right presupposes a more effective action, being absolutely necessary the commitment of the State to substantially increase investments in education, providing young people with knowledge that concerns the rights of every citizen, since it is paper Education and the State contribute to the process of solidification of Human Rights and the construction of citizenship, the basis of which is found in the Brazilian constitutional text.

Keywords: Wording; Right; Education; intellectual and critical training; Principle of Human Dignity.
\end{abstract}

\section{Introdução}

Essa pesquisa desenvolveu-se a partir da elevada e constante frequência dos temas de redações envolvendo o Direito que comumente vem sendo objeto principal a ser instigado e debatido nas coletâneas das principais bancas julgadoras. Pretendese demonstrar o quão são importantes as noções jurídicas para os alunos que se submeterão a escrita de uma redação, seja esta durante o Ensino Médio, seja posterior, visando o ingresso ao Ensino Superior, a concursos ou ao Exame Nacional do Ensino Médio (ENEM). No decorrer da pesquisa, busca-se retratar os modos básicos da redação e a educação como direito social disposto na Carta Magna. Doravante, demonstra-se que os temas de redação das principais bancas julgadoras de vestibular e do ENEM, envolvem conteúdos jurídicos.

De igual sorte, a Constituição Federal de 1988 chamada também de Constituição Cidadã, destaca a educação sendo esta um direito fundamental de todas as camadas sociais e destinando ao poder estatal total responsabilidade por sua promoção e incentivo com a colaboração da sociedade, coadunado à família, visando o pleno desenvolvimento da pessoa, o efetivo exercício em

*Endereço Eletrônico: kiko_marilia@hotmail.com prol da cidadania e sua qualificação para o trabalho.

Nesse viés, reza a mesma Carta Magna que o não-oferecimento do ensino obrigatório pelo Poder Público, ou sua oferta irregular, importa responsabilidade da autoridade competente (BRASIL, 1988). Por via de consequência, a educação apresenta um conjunto de elementos capazes de vincular, ainda que minusculamente, a atuação do governo com vistas à concretização do direito à educação e ratifica que tais conjuntos em última análise são dispositivos hábeis a gerar direitos subjetivos passíveis amplamente de tutela jurisdicional.

Portanto, é totalmente possível instituir o elo entre as garantias individuais e normas definidoras de direitos, garantias de qualidade e normas programáticas em que se vislumbra a incumbência estatal com a educação, haja vista ser um direito constitucional e, por esse fato, deve ser integralmente cumprido.

Assim, o artigo visa analisar quais noções jurídicas os estudantes precisam ter para produzirem textos aos quais são exigidos em alguns vestibulares e no Exame Nacional do Ensino Médio (ENEM). Assim, devido a incidência dos temas que já foram solicitados, deve-se refletir sobre a importância dos 
estudantes terem algumas noções jurídicas que poderão auxiliar na argumentação de textos produzidos. Foi utilizado o enfoque dedutivo e levantamento bibliográfico de alguns sites, "blogs", sites de jornal e de "dicas aos vestibulandos" que tratam a respeito, além da pesquisa qualitativa, cujo objetivo se deu devida constatação por meio das aulas ministradas para os jovens durante o Ensino Médio e Cursinho Pré-Vestibular.

Por fim, torna-se imprescindível a inclusão de noções jurídicas para os alunos, vestibulandos e concurseiros, uma vez que é papel fundamental e de responsabilidade do Estado arcar e dar suporte ao ensino nacional, no qual se cogitaria assim em falar em "Pátria Educadora".

\section{A redação e seus modos básicos}

A redação tem grande destaque nos concursos, vestibulares e no ENEM, e, infelizmente deixa muitos candidatos receosos no momento de transcrever para a folha suas ideias e argumentos. Entretanto, redigir um texto de maneira competente é imprescindível para o êxito da vida acadêmica e profissional, pois, comunicar-se bem é uma destreza que, além de abrir os horizontes, melhora as relações pessoais.

Para fazer um bom texto é indispensável a prática da leitura. Essa indispensabilidade propicia ao leitor a absorção de conhecimento, a formação de opinião crítica e novas maneiras de interpretar o mundo.

Nessa conjuntura, é claro que existem pessoas que possuem uma melhor relação com as palavras, pessoas que são dotadas de uma grande facilidade para expressar-se de maneira que serão integralmente compreendidas. $\mathrm{O}$ que essas pessoas têm de diferentes? A resposta é simples: bons escritores também costumam ser bons leitores. Jamais subestime a importância da leitura, pois é inegável o fato de que quem lê mais tem mais facilidade com a modalidade escrita (CASTRO, 2016).

Nesse panorama, destacam-se as modalidades de redação, usualmente utilizadas nos vestibulares e durante o ensino médio, além de também avaliar o texto realizado pelos alunos no Exame Nacional do Ensino Médio.

Lins (2013) relata as modalidades de redação, tendo a dissertação como o "texto que se caracteriza pela defesa de uma ideia, ponto de vista ou questionamento para abordar um determinado assunto". Assim, nessa modalidade de escrita, é permitida ao autor acrescentar julgamentos ou opiniões para defender sua tese, desde que se transmitam credibilidade e consistência, sem abandonar o formato de discurso persuasivo.

Nesse viés, a narração se caracteriza "pela representação de fatos reais ou fictícios, envolvendo personagens e fatos que ocorrem num determinado tempo e espaço". A narração de fatos reais é muito comum em livros científicos, jornais, livros de História e outros. Por sua vez, a narração de fatos fictícios não tem compromisso com a realidade e permite inventar e criar fatos de acordo com a imaginação de quem relata. Todo texto narrativo existe na medida em que há uma ação praticada por personagens e conta com dois elementos principais tempo e lugar. O narrador pode estar ou não embutido dentro dos acontecimentos e sofrer ações e intromissões de outros personagens de acordo com o contexto em que se passa a história. Os verbos neste tipo de texto são usados em primeira pessoa para personagens e em terceira pessoa quando um observador está contando algum fato (LINS, 2013).

Assinale, ainda, que, a descrição, segundo a autora, é o "termo descrever significa representar, por meio de palavras, as características de um objeto, uma ideia ou um sentimento". Um texto descritivo tem como objetivo transmitir informações sobre seu foco principal, de modo que o leitor crie na sua mente uma imagem do objeto, pessoa, sentimento ou ser descrito. Os pontos de vista existentes em uma descrição podem ser exibidos de duas maneiras: objetiva ou subjetiva. A forma objetiva e aquela que apresenta um objeto e indica suas características principais de maneira precisa, cuidando para que as palavras não permitam mais de uma interpretação. Já a forma subjetiva acontece quando se trabalha com a linguagem para selecionar palavras ricas de sentido e o emprego de construções livres que permitem mais de uma interpretação do leitor (LINS, 2013).

Por fim, é comum a afirmação de que a redação esteja entre as etapas mais complicadas do vestibular, uma vez que não possui um sistema préestabelecido, disposto através de tópicos como ocorrem nas outras disciplinas, caracterizadas pela predominância da logicidade. Nesse diapasão, visase mostrar no texto que escrever bem, implica na construção de um estilo próprio, uma forma pessoal de lidar com a linguagem.

Ensinar a escrever redação deixa de ser, portanto, uma tarefa positivista na qual se impõe um método de construção de texto, a metodologia como uma caixa de ferramentas e instrumento inibitório da criatividade do vestibulando (SANTOS, 2012). 
Desse modo, os mecanismos construtivos que dão sentido ao enunciado da proposta referente à redação busca compreender os valores institucionais que estabelecem uma cena fundante para o vestibulando, ou seja, àquela instituída como desafio pelo enunciador da prova e que se constitui em muitas das vezes, a ligação com o tema principal enfatizado nos textos de apoio.

Nesse ínterim, a descrição das vozes atravessa a redação, tais como: a do aluno; a do sujeito que formulou a proposta; a da sociedade. Depreende-se, por conseguinte, a imagem do enunciador das redações de vestibular como um sujeito dialógico, isto é, um sujeito que constrói de si e para si, a imagem daquele que enfrenta enunciativamente determinada situação de confronto, específica e pontual de avaliação, respondendo a outro (RAMOS, 2009).

Considerando que as habilidades de leitura e escrita não podem ser tomadas de forma separada da informação cultural que cada indivíduo possui, Hirsch Jr. (1988) afirma que o analfabetismo não é, simplesmente, incapacidade de ler e escrever, mas uma deficiência de informação cultural, que não pode ser remediada com métodos centrados exclusivamente na técnica ou no treinamento de habilidades.

Para Pugh e Pawan (1991), as chamadas dificuldades de leitura e redação referem-se, na verdade, as deficiências em capacidades cognitivas básicas, como a habilidade de compreender variáveis, fazer proposições, identificar lacunas de informação, distinguir entre observações e inferências, raciocinar hipoteticamente e exercitar a metacognição.

Assim sendo, a redação tem, pois, em concordância, o ato criativo e a liberdade de executar a escrita em prol do pensamento. De igual modo, resume-se em desafiar o aluno a se subjugar todas às vezes, objetivando o estilo próprio e sentir o entusiasmo do próprio texto.

\section{O direito à educação}

De início, a fim de analisar toda a dimensão do direito à educação, é preciso situá-lo, de antemão, no âmbito dos direitos sociais, econômicos e culturais, os denominados direitos de segunda geração, no contexto dos Direitos Fundamentais, com grande ênfase na Carta Magna de 1988.

A declaração do direito à educação parte da ideia de que todos têm direito a ela, admitindo-se, entretanto, que a diferença na sua oferta, ainda que possa existir, deva ser a menor possível. Ao se declarar que todos têm direito à educação, parte-se da ideia de que há uma igualdade subjacente à declaração: a igualdade de todos os cidadãos perante a lei, sendo a responsabilidade de o Estado buscá-la incessantemente nas políticas públicas. Assim, todas as circunstâncias que permitam a desigualdade na garantia desse direito devem ser evitadas, por contrariarem a própria ideia de direito (OLIVEIRA, 2012).

Destarte, reforçando a condição relevante dos Direitos Fundamentais, calha frisar que essa expressão retrata a sinonímia com a dos Direitos Humanos. Portanto, estes encontram seu fundamento de validade na preservação da humanidade, pois são reconhecidos pelo ordenamento jurídico como essenciais à existência da condição humana.

No que se refere a expressão fundamentalidade, oportunas são as palavras do jurista italiano Norberto Bobbio (2004, p. 05):

Os direitos fundamentais ou direitos humanos são direitos históricos, ou seja, são frutos de circunstâncias e conjunturas vividas pela humanidade e especificamente por cada um dos diversos Estados, sociedades e culturas. Portanto, embora se alicercem numa perspectiva jusnaturalista, os direitos fundamentais não prescindem do reconhecimento estatal, da inserção no direito positivo.

Nesse ínterim, através de uma visão humanista, a Constituição não se absteve de antever acerca da garantia à educação e assim o faz de forma implícita através dos princípios constitucionais, com destaque o Princípio da Dignidade da Pessoa Humana, mas também o faz de forma clara e explícita, como se relata nos artigos 6 e 205 da Carta Magna:

Artigo 6 - São direitos sociais a educação, a saúde, o trabalho, a moradia, o lazer, a segurança, a previdência social, a proteção à maternidade e à infância, a assistência aos desamparados, na forma desta Constituição. Artigo 205 - A educação, direito de todos e dever do Estado e da família, será promovida e incentivada com a colaboração da sociedade, visando ao pleno desenvolvimento da pessoa, seu preparo para o exercício da cidadania e sua qualificação para o trabalho (BRASIL, 1988).

O fato é que o direito à educação inserto na Lei Maior de 1988 está concatenado estreitamente 
ao reconhecimento da dignidade da pessoa humana como pilar de sustentação da República Federativa do Brasil e ainda com seus objetivos principais, quais sejam: a construção de uma sociedade livre, justa e solidária, o desenvolvimento nacional, a erradicação da pobreza e da marginalidade, redução das desigualdades sociais e regionais e a promoção do bem comum (BRASIL, 1988).

A educação das crianças está diretamente relacionada com a cidadania e quando o Estado garante que todas as crianças serão educadas, este tem em mente, sem sombra de dúvida, as exigências e a natureza da cidadania. Está tentando estimular o desenvolvimento de cidadãos em formação. $\mathrm{O}$ direito à educação é um direito social de cidadania genuíno porque o objetivo da educação durante a infância é moldar o adulto em perspectiva. Basicamente, deveria ser considerado não como o direito da criança frequentar a escola, mas como o direito do cidadão adulto ter sido educado. (MARSHAL, 1967, p. 73)

Entretanto, é na parte introdutória do texto constitucional que se define o direito à educação como sendo um direito social, portanto, de segunda geração e, mais a frente, diz sê-la um direito subjetivo, o qual deverá ser tutelado pelo Estado nos moldes da previsão da Carta Magna.

Dentro dessa ótica na defesa da educação pelo Estado, o artigo 208 é de grande pertinência ao tema que se enfrenta, portanto, merecedor de maior ênfase e atenção. Relatam-se os limites da responsabilidade do Estado acerca da educação em vários de seus incisos e parágrafos, aos quais se destacam principalmente:

Artigo 208. O dever do Estado com a educação será efetivado mediante a garantia de:

I - ensino fundamental, obrigatório e gratuito, assegurada, inclusive, sua oferta gratuita para todos os que a ele não tiveram acesso na idade própria;

II - progressiva universalização do ensino médio gratuito (BRASIL, 1988);

O que há de fundamental a esclarecer, diante disso, é que assiste ao Estado o dever com educação nacional, de modo que ofereça totais condições para que os alunos tenham conhecimento suficiente para suprir suas eventuais dúvidas na hora de serem avaliados numa prova como vestibular. Assim, Leonardo (2015) disserta sobre a função da escola na contribuição da cidadania:

A função da escola é formar jovens cidadãos, e ser cidadão é entre outras coisas, ter direitos e deveres igualitariamente perante os outros, sendo fundamental que o conhecimento sobre quais esses direitos e deveres do jovem seja ensinado nas instituições de ensino. É necessária ao menos uma noção básica sobre o funcionamento do poder estatal, sobre a elaboração de leis, o que confere sua legitimidade, e por que devemos obedecê-las e respeitá-las.

Afigura-se, nessa conjuntura, a importância de sedimentar à consequência da perspectiva destacada pelo autor, pois de acordo com a Constituição, faz-se necessária a intervenção estatal a fim de oferecer o ensino de qualidade, amalgamado ao vínculo entre o jovem e escola, no qual o estudante não só se realizará, mas também encontrará a objetivação sobre a sociedade que vive, satisfazendo seus interesses no tocante ao estudo e o Direito também o auxiliará em sua formação cidadã.

\section{O Direito como tema de redações das principais bancas avaliadoras de vestibulares e do ENEM}

Inicialmente, é mister sublinhar que as organizadoras de provas de vestibulares solicitaram do aluno o conhecimento de temas da sociedade hodierna, que, em sua maioria, envolvem o Direito. É imperioso enfatizar que, o estudo recente dos principais temas envolve também o Exame Nacional do Ensino Médio que também mantém a redação como critério para aprovação. Destacam-se as principais organizadoras das provas de redação para vestibulares:

- Universidade Estadual Paulista (UNESP):

O tema para a redação da Fundação para o Vestibular da Universidade Estadual Paulista (VUNESP), no vestibular da Faculdade de Medicina de Ribeirão Preto (FAMERP), em 2015, foi uma dissertação referente aos Impostos sobre Grandes Fortunas (IGF). Nesta perspectiva, cabe destacar que o referido imposto federal é previsto constitucionalmente, mas não regulamentado, ou seja, não pode ser aplicado. Em sua coletânea, elencou o pequeno texto para apoio com definição simples do imposto e em seguida, o tema da dissertação relatava sobre: "O imposto sobre grandes fortunas é uma injustiça com os mais ricos?" (LEWER, 2016).

Lourenço (2015) relata as provas da segunda fase do vestibular do meio de ano 2015 da UNESP, com o tema: redução da maioridade penal. Tal tema retrata conteúdos jurídicos que estão em 
evidência atualmente, seja na seara penal, quanto constitucional.

Por consequência, a redação da segunda prova da segunda fase do vestibular da Universidade Estadual Paulista (UNESP) em 2015, teve como tema "O legado da escravidão e o preconceito contra negros no Brasil". A prova teve ainda, 12 questões discursivas de linguagens e uma redação. A redação trouxe quatro textos de apoio: um sobre a Lei Áurea; um artigo sobre a participação do negro nas 500 maiores empresas do país; e dois trechos dos artigos "Racismo e antirracismo no Brasil" e "Nem preto nem branco, muito pelo contrário" (EDUCAAFRO, 2015).

No meio do ano de 2010, o tema foi "Os valores morais e sua importância na sociedade". Seguindo tal direção, incluem-se os dispositivos penais e constitucionais sobre o tema em que se enfatiza a honra como objeto central da discussão e sua violação podendo se tornar crime (PORTAL R7, 2012).

Assim sendo, o aluno com conhecimento jurídico básico sobre o tema, teria maior desenvoltura para redigir seu texto. Já no vestibular de 2009, a UNESP solicitou que os vestibulandos fizessem uma redação dissertativa sobre o tema " $O$ homem: inimigo do planeta?" No texto de apresentação do tema, a prova usava um personagem de uma peça de Millôr Fernandes que afirmava que "o homem é o câncer da Terra" e dizia que uma pessoa otimista não concordaria com o parecer. O tema faz com que o aluno desperte o senso crítico sobre a degradação ambiental e construa sua menção sobre o mesmo, uma vez que o meio ambiente é tutelado pela Constituição Federal. No vestibular do meio do ano de 2009 , a prova pedia que o aluno fizesse uma redação sobre a "A tecnologia e a invasão da privacidade". Textos da prova de língua portuguesa mostravam, de maneira direta, o interesse pela vida alheia e cuja tutela constitucional também é dirigida aos direitos à privacidade (PORTAL R7, 2012).

Outrossim, é possível ter uma ideia dos temas mais possíveis nos próximos vestibulares por meio da observação de tendências durante $o$ ano. Destacam-se questões políticas sendo discutidas, temas sobre corrupção, moralidade, violência serão cabíveis.

- Fundação Universitária para o Vestibular (FUVEST):

Inicialmente, destaca-se que a redação da FUVEST equivale à metade dos 100 pontos do primeiro dia de provas, sendo importante redigir muito bem o texto.

A participação política foi o tema da redação do vestibular aplicado em 2012. Assim sendo, foi apresentado com três textos em prosa, um texto em verso e uma tirinha do cartunista Adão Iturrusgarai publicado em 2011. Um dos textos tratava da origem da palavra "idiota" $(\mathrm{G} 1,2015)$.

Cabe destacar que tal assunto é destaque na Constituição Federal de 1988 e expressa de várias formas, como por exemplo, os chamados Projetos de Lei de Iniciativa Popular, a Ação Civil Pública que era exclusiva de entes públicos como o Ministério Público, a Defensoria Pública, a União, Estados e Municípios, agora também pode ser proposta por qualquer entidade da sociedade civil. Há também instrumentos como as audiências públicas, os conselhos municipais, plebiscitos, referendos, conselhos de direitos, conselhos tutelares e outros (BRASIL, 1988).

Finalmente, a redação em 2014 teve como tema o envelhecimento populacional e as formas de se lidar com os cuidados médicos, diante da população ao final da vida. Dessa vez, sem uma pergunta que definisse um tema específico a prova exigiu que os candidatos considerassem as diversas implicações éticas, culturais, sociais e econômicas do Brasil para redigir um texto dissertativo que pudesse ser publicado em jornais, revistas ou sites jornalísticos (G1, 2015).

- Universidade Estadual de Campinas (UNICAMP):

Em 2015, a Unicamp solicitou de seus vestibulandos temas que abrangessem a saúde no Brasil e a violência nas escolas. Sobre saúde, direito social tutelado pela Lei Maior, destacou-se o tema sobre a humanização no atendimento à saúde, que deveria ser escrito em registro formal, sendo as fontes para escrever a síntese, retiradas e analisadas dos trechos de um artigo científico e de um ensaio, sintetizando-os de modo a contemplar no texto:

- o conceito de humanização no atendimento à saúde;

- o ponto de vista de cada texto sobre o conceito, assim como as principais informações que sustentam esses pontos de vista;

- as relações possíveis entre os dois pontos de vista (UNICAMP, 2015).

Nessa esteira, o outro tema solicitado dispunha acerca da violência no âmbito escolar e contemplava a elaboração de uma carta-convite que deveria convencer os membros da comunidade escolar a participarem de uma reunião, justificando a importância desse espaço para a discussão de ações 
concretas de enfrentamento do problema da violência na escola, isso para construir seus argumentos e mostrar possibilidades de solução (UNICAMP, 2015).

- Universidade Federal de São Paulo (UNIFESP):

A violação dos Direitos Humanos ocorridos durante a ditadura militar compôs a coletânea da Unifesp em 2013, destacando a Comissão da Verdade. Nesse ínterim, a coletânea dispunha acerca da definição da Comissão:

O objeto da Comissão da Verdade deve, sim, tratar dos crimes e dos desaparecimentos perpetrados pelos agentes do Estado ditatorial. É sua tarefa precípua e estatutária. Mas não pode se reduzir a estes fatos. Há o risco de os juízos serem pontuais. Precisa-se analisar o contexto maior, que permite entender a lógica da violência estatal e que explica a sistemática produção de vítimas. Mais ainda, deixa claro o trauma nacional que significou viver sob suspeitas, denúncias, espionagem e medo paralisador (UNIFESP, 2013).

Por esse prisma, baseado na coletânea apresentada (três textos) e em nos próprios conhecimentos do aluno, exigiu-se que redigissem um texto dissertativo, obedecendo à norma-padrão da língua portuguesa, sobre o tema: Comissão da Verdade: que verdade alcançar?

- Pontifícia Universidade Católica de São Paulo (PUC-SP)

Para o vestibular de 2014, a PUC-SP suscitou como tema o anonimato na Internet, elencando em sua coletânea o inciso IV do artigo $5^{\circ}$ da Constituição Federal relatando que: "É livre a manifestação do pensamento, sendo vedado o anonimato (BRASIL, 1988)".

A proposta destacava o texto do jornalista Eugênio Bucci que explorava pontos positivos e negativos sobre o tema anonimato na Internet. Solicitou-se a construção de um texto dissertativoargumentativo sobre o assunto (PUC, 2014).

- Exame Nacional do Ensino Médio (ENEM)

A prova de redação do ENEM está presente desde a edição inaugural do exame em 1998. Nesse cenário, abordou sempre temas de ordem social e cultural, cujos reflexos se manifestam nas realidades políticas, históricas nacionais e na cidadania engendrando ao aluno a construção crítica.

A prova de redação do ENEM faz parte da matriz de referência de Linguagens, Códigos e suas Tecnologias, já que esta abrange os conteúdos de Língua Portuguesa como gramática normativa, interpretação de textos e produção textual. $\mathrm{O}$ exame segue a tradição da maioria dos vestibulares do país: incluir uma avaliação de produção textual que, na verdade, não avalia apenas a escrita do candidato, mas também a leitura (POZZA PEREIRA, 2015).

Em vista disso, os temas de todas as propostas de redação do ENEM, desde sua concepção até o ano de 2015 foram:

2015 - A persistência da violência contra a mulher na sociedade brasileira;

2014 - Publicidade infantil em questão no Brasil;

2013 - Efeitos da implantação da Lei Seca no Brasil;

2012 - Movimento imigratórios para o Brasil no século XXI;

2011 - Viver em rede no século XXI: os limites entre o público e o privado;

2010 - O trabalho na construção da dignidade humana;

2009 - O indivíduo frente à ética nacional;

2008 - Como preservar a floresta Amazônica: suspender imediatamente o desmatamento; dar incentivos financeiros a proprietários que deixarem de desmatar; ou aumentar a fiscalização e aplicar multas a quem desmatar;

2007 - O desafio de se conviver com as diferenças;

2006 - O poder de transformação da leitura;

2005 - O trabalho infantil na sociedade brasileira;

2004 - Como garantir a liberdade de informação e evitar abusos nos meios de comunicação;

2003 - A violência na sociedade brasileira: como mudar as regras desse jogo;

2002 - O direito de votar: como fazer dessa conquista um meio para promover as transformações sociais que o Brasil necessita?;

2001 - Desenvolvimento e preservação ambiental: como conciliar os interesses em conflito?;

2000 - Direitos da criança e do adolescente: como enfrentar esse desafio nacional;

1999 - Cidadania e participação social;

1998 - Viver e aprender (GUIA DO ESTUDANTE, 2015).

Por conseguinte, os temas apresentados suscitaram aos candidatos o conhecimento básico jurídico na qual o apoio se dava desleixadamente nos textos da coletânea. Por esse prisma, Pozza Pereira (2015) assevera a postulação dos temas do exame, pois deles advêm os conteúdos jurídicos:

Podemos dizer que até 2003 os temas eram abordados de uma forma mais abrangente e 
generalizada e que a partir de 2004 essa abordagem passou a ser mais específica e detalhada, focando um determinado aspecto. Porém, desde o início do Enem, os temas têm enfoque social, abordando assuntos fundamentais como cidadania, direitos humanos, meio ambiente, educação, convívio social, ética, política, liberdade, comunicação etc. Por vezes, um mesmo tema abrange vários destes subtemas; por exemplo, o tema da prova de 2007 "O desafio de se conviver com as diferenças" engloba a questão da discriminação, dos inúmeros preconceitos (que, infelizmente, ainda estão enraizados na sociedade, não só brasileira) e, portanto, do convívio social e da liberdade de expressão, tanto corporal, sexual, religiosa, de informação, dentre outras (POZZA PEREIRA, 2015).

Em decorrência disso, tem-se também, além do destaque ao caráter cidadão e os direitos citados pela autora, os direitos das crianças e adolescentes, o direito de votar, formas de violência, o mais recente tema tratava da opressão contra mulheres, trabalho infantil e o trabalho na construção da dignidade humana e a lei-seca. Outrossim, não houveram apenas temas da realidade brasileira, pois a questão da imigração engloba ocorrências internacionais, como a devastação do Haiti, a crise na Zona do Euro e a busca por qualidade de vida dos latino-americanos que imigram para outros países.

Klein, Fontanive e Elliot (2007) afirmam que a proposta para a redação no ENEM tem sido elaborada de forma a possibilitar que o participante, com base nos subsídios oferecidos pela leitura da coletânea de textos-estímulo, organize dados do seu repertório e elabore argumentos que lhe permitam realizar uma reflexão crítica sobre um tema, em tarefa identificada como situação-problema. Neste contexto, a Redação possibilita avaliar o desempenho do participante como produtor de um texto ou como sujeito que escreve a realidade, fundamentando-se em um ângulo especial de leitura; avalia competências e habilidades relativas tanto à leitura quanto à escritura do mundo, com destaque para a qualidade da expressão escrita. Espera-se do participante que construa seu projeto de texto dissertativo-argumentativo com as características que estão sugeridas na proposta de redação.

Nessa linha de pensamento, sobressai a ideia que o texto é onde se organiza os componentes da expressão que estão à disposição do enunciador a fim de veicular seu discurso, sendo que este é o lugar da materialização das formações discursivas e pertence ao nível do conteúdo.

Diante do exposto, extrai-se que os temas das redações oriundos da coletânea são inerentes "às figuras das formações discursivas existentes na formação social em que está inserido" na qual se elaborará a síntese textual visando à conclusão coerente e coesa baseado com o que foi fundamentado (FIORIN, 2004, p. 41).

Em suma, vislumbra-se que o Direito como tema das redações vincula-se ao fato de se melhor compreender a sua dimensão no bojo da sociedade. Como exposto, evidencia-se a relevância e a premência do conteúdo jurídico com o propósito de contribuir para a Educação, além da constituição da cidadania e para a vida em sociedade.

\section{Considerações Finais}

Apresentou-se um estudo sobre os assuntos jurídicos que embasam os temas das redações em vestibulares e no ENEM, isso sob o enfoque da efetividade do direito à educação baseado nos direitos humanos e fundamentais e na dignidade da pessoa humana.

Assim sendo, procurou-se analisar, a princípio, os principais modos de redigir uma redação cuja avaliação é imprescindível em provas visando o acesso ao Ensino Superior ou em um concurso/processo seletivo.

Por esse prisma, pode-se afirmar que o vestibulando se compromete a fazer sua redação conforme as expectativas da instituição. Assim sendo, torna-se modalizado pelo querer e pelo dever, escreve de modo a agradar e mostrar-se solidário aos valores disseminados pelos temas e figuras no enunciado da proposta na qual o direito tem papel fundamental.

Considera-se também que os temas de cunho jurídico podem se transformar em fortes aliados do ensino, orientados por competências e habilidades cognitivas, uma vez que seus resultados vêm evidenciando no cotidiano escolar, na qual seu conhecimento prévio é um elo importante ao candidato que se submeterá a uma redação ou produção textual.

Apesar do desempenho dos candidatos ser fortemente condicionado a fatores extraescolares como, por exemplo, o nível socioeconômico, compete ao Estado fornecer meios cabíveis para que o aluno tenha o conhecimento necessário a fim de satisfazer suas dúvidas na elaboração da redação e, aos professores, intervirem nessa realidade, 
orientando sua prática pedagógica para desenvolver nos vestibulando as competências e habilidades requeridas pela banca examinadora, de modo a minimizar os efeitos dos fatores sócio-econômicosculturais nos resultados dos candidatos.

\section{Referências}

BOBBIO, Norberto. A Era dos Direitos. Trad. de Carlos Nelson Coutinho. Rio de Janeiro: Campus, 2004. p. 5.

BRASIL. Constituição Da República Federativa do Brasil de 1988. Disponível em: <http://www.planalto.gov.br/ccivil_03/constituicao/co nstitui\%C3\%A7ao.htm>. Acesso em: $17 \mathrm{dez} 15$.

CASTRO, Luana. Redação. 2016. Disponível em http://brasilescola.uol.com.br/redacao/. Acesso em 16 mai 16.

EDUCAAFRO. Vestibular Unesp 2015 tem redação sobre escravidão e preconceito racial. 2016. Disponível em http://www.educafro.org.br/site/vestibular-unesp2015-tem-redacao-sobre-escravidao-e-preconceitoracial/. Acesso em 25 mai 16.

FIORIN, José Luiz. O Páthos do enunciatário, Alfa. Revista de Linguística, São Paulo: UNESP, v. 48, p. 69-78, 2004.

G1. Relembre os últimos 5 temas da redação da Fuvest. $2015 . \quad$ Disponível em http://g1.globo.com/educacao/noticia/2015/01/relem bre-os-ultimos-5-temas-da-redacao-da-fuvest.html. Acesso em 25 mai 16.

HIRSCH JR., Eric. D. (1988). Cultural Literacy. New York: Vintage Books (Random House).

KLEIN, Ruben; FONTANIVE, Nilma Santos; ELLIOT, Ligia Gomes. $O$ exame nacional do ensino médio-Tecnologia e principais resultados em 2005. REICE: Revista Electrónica Iberoamericana sobre Calidad, Eficacia y Cambio en Educación, 2007.

LEONARDO, Francisco Antonio Morilhe. Introdução do Ensino do Direito no Currículo de Sociologia, no Ensino Médio, da Escola Pública.
2015. Revista Jurídica Luso Brasileira, Ano 1 (2015), n 3. P. 661-681.

LEWER, Laura. Temas de redação no Enem e em mais 25 vestibulares: veja o que caiu. 2016. Site Globo. Disponível em http://g1.globo.com/educacao/enem/2016/noticia/2016 /03/temas-de-redacao-no-enem-e-em-mais-25-ves tibulares-veja-o-que-caiu.html. Acesso em 26 mai 16.

LINS, Renata. Tipos de redação. 2013. Disponível em http://redeglobo.globo.com/sp/tvtribuna/cameraeducacao/platb/2013/09/06/tipos-de-redacao/.

Acesso em 24 mai 16.

LOURENÇO, Ana. Tema da redação foi destaque na segunda fase da Unesp de meio de ano 2015. $2015 . \quad$ Disponível em http://guiadoestudante.abril.com.br/vestibularenem/tema-redacao-foi-destaque-segunda-faseunesp-meio-ano-2015-876360.shtml. Acesso em 26 mai 16.

MARSHALL, Thomas Humphrey. Cidadania, classe social e status. Rio de Janeiro: Zahar, 1967.

OLIVEIRA, Romualdo Luiz Portela de. Direito à educação e federalismo no Brasil. Retratos da Escola, v. 6, n. 10, p. 39-47, 2012.

PORTAL R7. Confira os temas das últimas redações da Unesp. 2012. Disponível em http://noticias.r7.com/educacao/fotos/confira-ostemas-das-ultimas-redacoes-da-unesp-201212142.html\#fotos. Acesso em 26 mai 16.

POZZA PEREIRA, Camila Dalla. Veja Todos os Temas da Redação do Enem. 2015. Disponível em https://www.infoenem.com.br/veja-todos-os-temasda-redacao-enem/. Acesso em 04 jun 16.

PUC. Vestibular 2014. Disponível em http://www.cpv.com.br/cpv_vestibulandos/redacoes /puc/PUCSP_2014.pdf. Acesso em 04 jun 16.

PUGH, Sharon L.; PAWAN, Faridah (1991). Reading, Writing, And Academic Literacy. R. F. Flippo E D. \& Caverly, C. (Eds.), College Reading And Strategy Programs, Newark: Ira.

RAMOS, Rita de Cássia Antônia Nespoli. Redações de Vestibular: Preservar a própria face. 2009. UFSCAR. Revista Linguagem. 11 ed. Disponível 
em http://www.letras.ufscar.br/linguasagem/edicao1 1/artigo04.pdf. Acesso em 29 jul. 16.

SANTOS, Ernaldo Francisco dos. Escrever bem! 2012. Disponível

em http://ernaldicas.blogspot.com.br/2012/03/escreverbem.html. Acesso em 24 mai 16.

GUIA DO ESTUDANTE. 2015. Veja todos os temas de redação que já caíram no Enem. Disponível em http://guiadoestudante.abril.com.br/fotos/veja-todos -temas-redacao-ja-cairam-enem-690408.shtml\#0. Acesso em 04 jun 16.

UNICAMP. Vestibular 2015. Disponível em http://www.cpv.com.br/cpv_vestibulandos/redacoes /unicamp/Unicamp\%202015\%20Redacao.pdf. Acesso em 04 jun 16.

UNIFESP. Vestibular 2013. Disponível em http://www.cpv.com.br/cpv_vestibulandos/redacoes /unifesp/UNIFESP_2013.pdf. Acesso em 04 jun 16.

\section{Sobre o autor}

Francisco Antonio Morilhe Leonardo é Mestre em Didática do Ensino do Direito - UNIVEM - Centro Universitário Eurípides de Marília.

Recebido em Agosto de 2016.

Aprovado em Dezembro de 2016. 